\title{
Conceptualizing the Impact of Dust-Contaminated Infrared Radiances on Data Assimilation for Numerical Weather Prediction
}

\author{
Jared W. Marquis, ${ }^{\mathrm{a}}$ Mayra I. Oyola, ${ }^{\mathrm{b}}$ James R. CAmpbell,${ }^{\mathrm{c}}$ Benjamin C. Ruston, ${ }^{\mathrm{c}}$ \\ Carmen Córdoba-Jabonero, ${ }^{\mathrm{d}}$ Emilio Cuevas, ${ }^{\mathrm{e}}$ Jasper R. Lewis, ${ }^{\mathrm{f} g}$ \\ TRAVIS D. TOTH, ${ }^{\text {h }}$ AND JIANGLONG ZHANG ${ }^{\text {a }}$ \\ a Department of Atmospheric Sciences, University of North Dakota, Grand Forks, North Dakota \\ ${ }^{\mathrm{b}}$ Jet Propulsion Laboratory, Pasadena, California \\ ${ }^{\mathrm{c}}$ Naval Research Laboratory, Monterey, California \\ d Instituto Nacional de Técnica Aeroespacial, Torrejón de Ardoz, Madrid, Spain

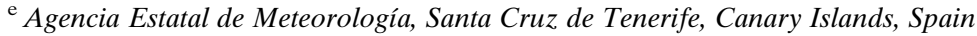 \\ ${ }^{\mathrm{f}}$ NASA Goddard Space Flight Center, Baltimore, Maryland \\ ${ }^{\mathrm{g}}$ University of Maryland, Baltimore County, Baltimore, Maryland \\ ${ }^{\mathrm{h}}$ Lidar Science Branch, NASA Langley Research Center, Hampton, Virginia
}

(Manuscript received 23 July 2020, in final form 29 September 2020)

\begin{abstract}
Numerical weather prediction systems depend on Hyperspectral Infrared Sounder (HIS) data, yet the impacts of dust-contaminated HIS radiances on weather forecasts has not been quantified. To determine the impact of dust aerosol on HIS radiance assimilation, we use a modified radiance assimilation system employing a one-dimensional variational assimilation system (1DVAR) developed under the European Organisation for the Exploitation of Meteorological Satellites (EUMETSAT) Numerical Weather Prediction-Satellite Application Facility (NWP-SAF) project, which uses the Radiative Transfer for TOVS (RTTOV). Dust aerosol impacts on analyzed temperature and moisture fields are quantified using synthetic HIS observations from rawinsonde, Micropulse Lidar Network (MPLNET), and Aerosol Robotic Network (AERONET). Specifically, a unit dust aerosol optical depth (AOD) contamination at $550 \mathrm{~nm}$ can introduce larger than 2.4 and $8.6 \mathrm{~K}$ peak biases in analyzed temperature and dewpoint, respectively, over our test domain. We hypothesize that aerosol observations, or even possibly forecasts from aerosol predication models, may be used operationally to mitigate dust induced temperature and moisture analysis biases through forward radiative transfer modeling.
\end{abstract}

KEYWORDS: Lidars/Lidar observations; Remote sensing; Satellite observations; Soundings; Data assimilation; Aerosols/particulates

\section{Introduction}

The atmospheric science community has become largely dependent on the growing database of operational satellite atmospheric remote sensing observations for weather monitoring, analysis, and forecasting (e.g., Rabier 2005; Mecikalski and Bedka 2006). In particular, Hyperspectral Infrared Sounder (HIS) observations, which are ingested into numerical weather prediction (NWP) models through data assimilation (DA), are a critical component of NWP, directly causing significant temperature and moisture forecast skill increases via radiance assimilation (e.g., Le Marshall et al. 2005; Chahine et al. 2006; Le Marshall et al. 2006; Smith et al. 1970; Guidard et al. 2011; Hilton et al. 2012; Menzel et al. 2018). For instance, Fig. 1 shows the number of satellite observations ingested within 30 days of assimilation cycles ending on 1 June 2017, and their contribution to the reduction of the 24-h forecast error norm ( $\mathrm{J} \mathrm{kg}^{-1}$; calculated using adjoints of the forecast model and data assimilation system; Langland and Baker 2004), for the

¿ Denotes content that is immediately available upon publication as open access.

Corresponding author: Jared W. Marquis, jared.marquis@und.edu
U.S. Navy Global Environmental Model (NAVGEM; Hogan et al. 2014). HIS measurements from the Cross Track Infrared Sounder (CrIS; Bloom 2001), Infrared Atmospheric Sounding Interferometer (IASI; Siméoni et al. 1997) and the Atmospheric Infrared Sounder (AIRS; Aumann and Pagano 1994), provide the most data counts by far, and consequently the significant decreases in forecast error norm, with CrIS and IASI causing the largest reduction of forecast error norm of all assimilated sensors.

While HIS radiance assimilation is a critical NWP element, oftentimes users are unaware to the underlying presumption of clear sky inherent to the assimilation of any given pixel. As HIS brightness temperatures are assumed to change only due to temperature and humidity differences, the presence of any other nonconstant radiance contributors (i.e., clouds and aerosols) must be screened. Most commonly, the screening is based on observed minus simulated brightness temperatures (hereafter: innovations). A common such approach is described by the European Organisation for the Exploitation of Meteorological Satellites (EUMETSAT) Numerical Weather Prediction-Satellite Application Facility (NWP-SAF) package Cloud and Aerosol Detection Software (CADS). The procedure was based on using spectral signatures of the innovations ranked by transmittance to detect departures indicating presence of cloud and aerosol impact (McNally and Watts 2003; Eresmaa 2014). For instance, 


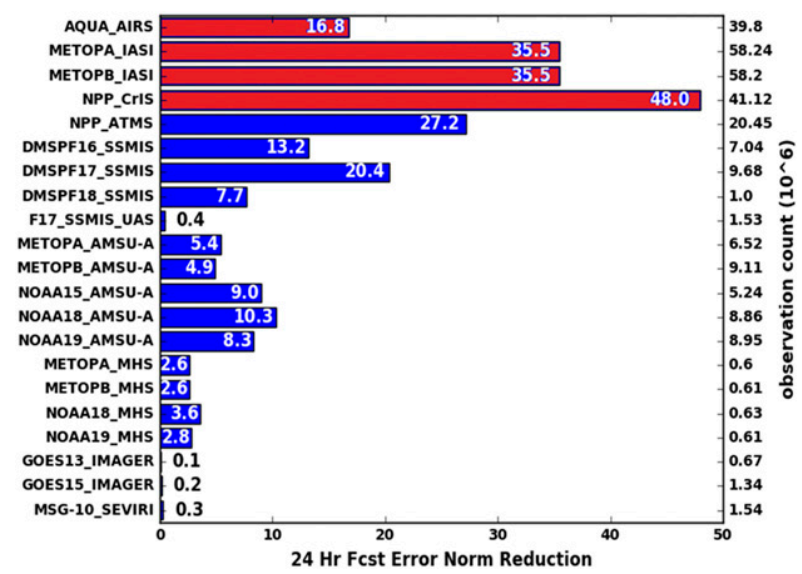

FIG. 1. Reduction of a 24-h forecast error norm $\left(\mathrm{J} \mathrm{kg}^{-1}\right)$ for the U.S. Navy operational global weather forecast model, NAVGEM, for 30 days of assimilation cycles ending on 1 Jun 2017 with current HIS instruments highlighted in red.

the Navy Atmospheric Variational Data Assimilation SystemAccelerated Representer (NAVDAS-AR), is the operational four-dimensional variational (4DVAR) DA system serving the U.S. Navy's global weather model, NAVGEM. In general, innovations above 3 times the observation error are screened. For mid- to low-tropospheric peaking wavelengths, this corresponds to approximately a $3 \mathrm{~K}$ screen in NAVDAS-AR. Additionally, discontinuities in innovations are used to screen cloud (McNally and Watts 2003; Eresmaa 2014). For NAVDAS-AR, this discontinuity threshold corresponds to an innovation of approximately $0.5 \mathrm{~K}$. The screening procedures filter nearly $99 \%$ of possible satellite data inputs for every 6-h DA window through quality control (QC), which includes spatial and temporal data thinning, and the innovation checks including inconsistent top-of-the-atmosphere HIS radiances (e.g., Campbell et al. 2017). At some tolerance threshold, however, relatively diffuse cloud and aerosol pixels pass through QC screening and the contaminated radiances are assimilated without prejudice (e.g., see discussion related to Fig. 2 below). Given the global predominance of contamination by optically thin cirrus clouds (>20\%; e.g., Sassen et al. 2008; Marquis et al. 2017) and aerosols (ever present; e.g., Zhang et al. 2016; Oyola et al. 2019) in models and remotely sensed datasets, an uncharacterized bias is very likely present in HIS assimilation systems from these particulates. In this study, we will focus on the aerosol, and particularly mineral dust, which are most likely to be active infrared (IR) emitters and hence threats to the HIS clear-sky assimilation assumption.

Impacts due to passive satellite-based IR radiance contamination of dust and optically thin cirrus clouds on IR observations have been reported. For example, tropical sea surface temperature (SST) retrievals have been found unscreened for optically thin cirrus cloud contamination at frequencies over 30\% (Marquis et al. 2017). In a similar vein, dust and other aerosols have been shown to contaminate IR-SST retrievals (e.g., Merchant et al. 1999; Bogdanoff et al. 2015). For HIS radiances specifically, through an idealized study,
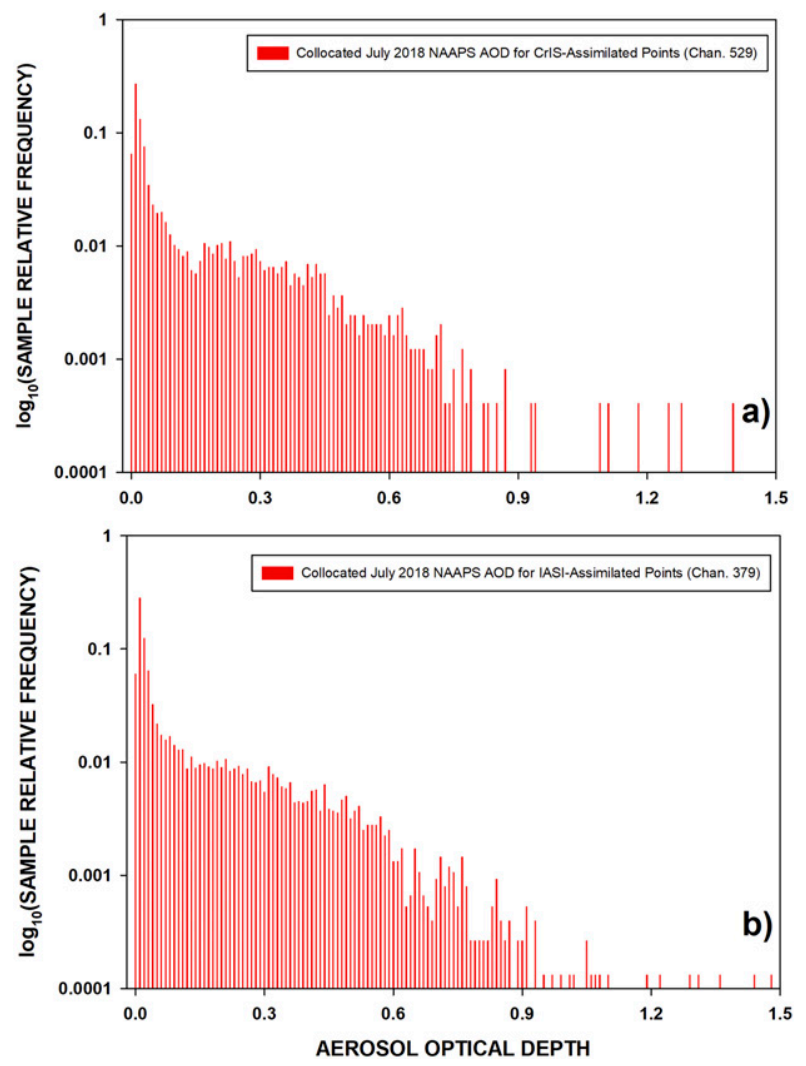

FIG. 2. Relative histograms of aerosol optical depth from NAAPS and assimilated points in NAVGEM for the (a) Hyperspectral Infrared Sounders CrIS channel $713\left(980 \mathrm{~cm}^{-1}\right)$ and (b) IASI channel $379\left(739.50 \mathrm{~cm}^{-1}\right)$ for July 2018.

Pierangelo et al. (2004; hereafter P04) showed that dust can induce IR brightness temperature biases of $\sim 10 \mathrm{~K}$. Although this theoretical study broadly outlines the potential for dust contamination, the experiment (as we will show) was highly idealized, and hence no subsequent work has been done demonstrating the effect with real observations or the consequences of assimilating biased HIS radiances on analyzed temperature and moisture fields.

Despite the significant aerosol-induced cold biases on HIS radiances, screening of radiances for aerosol contamination is not perfect, and residual aerosol contamination persists. The histogram of assimilated HIS observations into the Navy Global Environmental Model (NAVGEM) for July 2018 as shown in Fig. 2. Here, the histogram of combined observations from CrIS channel $529\left(980 \mathrm{~cm}^{-1} / 10.2 \mu \mathrm{m}\right)$ and IASI channel $379\left(739.5 \mathrm{~cm}^{-1} / 13.5 \mu \mathrm{m}\right)$ are plotted as a function of aerosol optical depth (AOD) from the Navy Aerosol Analysis and Prediction System (NAAPS). These bands are the lowest-altitude peaking channels regularly assimilated in NAVDAS-AR for the CrIS and IASI sensors, and typically exhibit sensitivity in a broad range from the surface to $5-8 \mathrm{~km}$. The CrIS channel peaks closer to the surface than the IASI channel-peaking near $950 \mathrm{hPa}(\sim 0.5 \mathrm{~km})$ while the IASI channel temperature exhibits a Jacobian peak near $600 \mathrm{hPa}(\sim 4.5 \mathrm{~km})$. Note, a relative frequency 
of 1 corresponds to 11156 observations (i.e., all assimilated observations) while a frequency of 0.001 corresponds to $0.1 \%$ of all observations ( $\sim 11$ points). Here, $16.2 \%$ of IASI/CrIS assimilated observations occur over regions identified by NAAPS as having an $\mathrm{AOD} \geq 0.30$ - the threshold at which dust-induced temperature biases after assimilation become greater the NAVGEM typical uncertainty (discussed later). While the NAAPS AOD represents model analysis, the NAAPS analysis fields are highly correlated with observations (Zhang et al. 2014; Lynch et al. 2016). Thus, aerosol contamination within assimilated HIS radiances is likely significant, with contamination possibly resulting in important, yet unquantified, impacts postassimilation. For reference, typical background uncertainties in the free troposphere in NAVGEM are assumed to be below $0.4 \mathrm{~K}$ for temperature. NWP models struggle more with moisture, with NAVGEM exhibiting uncertainties $(\sim 20 \%)$ that are significantly higher than those for temperature.

With multiple HIS-equipped satellite sensors expected to launch within the next decade (e.g., Menzel et al. 2018), the community can only become further dependent on these data sources as a means for optimizing NWP accuracy. Despite the current dependence on HIS radiances for NWP, outstanding uncertainties inherent to the data have yet to be properly characterized, specifically the impacts of aerosols and clouds. Once properly characterized, attempts to mitigate such uncertainties can be performed, either by way of active correction, or better bias estimation. This study makes use of the Micropulse Lidar Network (MPLNET; Welton et al. 2001)Aerosol Robotic Network (AERONET; Holben et al. 1998) combined ground-based dust aerosol profiling (Welton et al. 2002; Campbell et al. 2002) and a modified EUMETSAT 1DVAR system (Hilton 2016) to examine the effects of physically realistic dust plumes on HIS brightness temperatures. Our first goal, in a somewhat similar vein to P04, is to characterize the impact of observed dust profiles on HIS measured radiance. These radiance impacts are then translated to analyzed temperature and moisture impacts in an idealized 1D framework. Finally, we show that observations of dust can be used to mitigate the impact of dust on HIS radiance assimilation.

\section{Datasets and methodology}

Our experiments are conducted using aerosol and meteorological measurements collected at Santa Cruz de Tenerife, Spain $\left(28.48^{\circ} \mathrm{N}, 16.34^{\circ} \mathrm{W}, \mathrm{UTC} \pm 0 \mathrm{~h}, 0.52 \mathrm{~km}\right.$ above mean sea level; all heights MSL), from June through November 2008-09 and 2011-14 and through the use of a modified 1DVAR assimilation system described below. Observed parameters are daytime total column AOD retrieved from AERONET, aerosol vertical distributions from the ground-based MPLNET lidar, and tropospheric temperature and moisture profiles from World Meteorological Organization compliant rawinsonde launches conducted every $12 \mathrm{~h}$ on the island. Santa Cruz de Tenerife, Spain, is chosen for this study as coincident observations of all required parameters are regularly available, and, the island is just off the west coast of Saharan Africa, where dust aerosol events are frequent (Rodríguez et al. 2011).
Coincident atmospheric profiles from Modern-Era Retrospective Analysis for Research and Applications, version 2 (MERRA-2; Gelaro et al. 2017), are used to supplement local rawinsonde data, for concurrent experiments to examine the impacts of dust in a more realistic operational setting. Specifically, MERRA-2 meteorological profiles are used as the first-guess atmosphere during assimilation with dust-biased HIS radiances to determine if providing vertical aerosol information during assimilation can mitigate the effects of unscreened aerosol.

\section{a. 1DVAR system and experimental design}

\section{1) THE 1DVAR SYSTEM}

The version 1.1 EUMETSAT 1DVAR system, which couples version 11.2 Radiative Transfer for TOVS (RTTOV; Saunders et al. 2018) as a forward model for innovation and Jacobian calculations, is used. By default, the 1DVAR system is built around a "clear-sky" assumption and thus does not consider aerosols in its calculations. RTTOV has built-in aerosol capability, yet is disabled in the 1DVAR interface to RTTOV by default. We include the effect of aerosols by enabling aerosol calculations and by adding a new function to the 1DVAR system to ingest input aerosol properties. In theory, by including aerosols in forward model calculations, aerosol impacts are also included in the background top-of-atmosphere (TOA) radiance calculations, and subsequent background-versus-observation innovations. Therefore, by enabling or disabling the aerosol calculations in RTTOV, the impacts of aerosols on analyzed temperature and moisture fields can be isolated and quantified. Note, because we depend upon the 1DVAR system coupled with RTTOV, our results are dependent upon the accuracy of RTTOV's forward operator and Jacobian calculations.

To be consistent with RTTOV, which uses the Optical Properties of Aerosols and Clouds, version 3.1 (OPAC; Hess et al. 1998), database for aerosol calculations (Saunders et al. 2018), the 1DVAR system is modified to include the ability to ingest an aerosol number concentration profile with up to 10 aerosol species corresponding to those defined in the OPAC database. This includes soot (insoluble and water soluble), sulfate, sea salt (accumulating and coarse mode) and mineral dust (accumulating, nucleating, coarse, and transported mode). By allowing for 10 individual aerosol species, the 1DVAR system can inform the RTTOV system with any mixture of aerosols for consideration during radiance calculations.

Both background and observational error covariance matrices are needed for the 1DVAR radiance assimilation. For demonstration purposes, the default 54-level background error covariance matrix included with the $1 \mathrm{DVAR}$ system package is used (Weston et al. 2014). Note that background error covariance matrices are model specific. Since this default background error covariance matrix is used, our results may be over or underestimated for a specific model application. That said the use of a static background error covariance matrix helps to constrain the variability between the different individual case runs, helping to isolate the impact of the dust in our bulk results. We constrain our study to the CrIS sensor aboard the Suomi NPP satellite. As an appropriate proxy for observational applications, the observational error covariance matrix for CrIS used 
is the default one contained in the EUMETSAT NWP-SAF 1DVAR package (Hilton 2016). The CrIS sensor was chosen due to its primary role within the Joint Polar Satellite System satellites (with use extending into the 2030s) and demonstrated impacts in NWP (e.g., Fig. 1; Goldberg et al. 2013, and references therein). Aerosol and meteorological parameters are then interpolated to the pressure levels defined with the default background error covariance matrix discussed above.

\section{2) EXPERIMENTAL DESIGN WITH THE USE OF THE 1DVAR SYSTEM}

In an optimal experimental framework, collocated observations of atmospheric temperature, humidity, and aerosol profiles would be obtained with the CrIS HIS TOA radiance spectra at the footprint resolution of that particular HIS sensor. However, there are representivity issues collocating HIS radiances with point measurements provided by the available rawinsonde network. Relative to the Tenerife study site, CrIS has an equatorial overpass time of $\sim 1330$ local time ( $\sim 1330$ UTC), while rawinsonde measurements are taken at midnight and noon local time (0000 and 1200 UTC, respectively). Even if collocated rawinsonde-CrIS data were available, these representativeness issues arise due to the spatially integrated nature of the satellite observations versus the pointbased observation from rawinsondes. Besides representativeness issues, using collocated data is suboptimal, as additional uncertainties associated with surface emissivity and the aerosol models may cause noise indistinguishable from the aerosol impact. Thus, in an attempt to isolate the aerosol impact, simulated rather than observed CrIS HIS radiances at the normal spectral resolution (NSR; 1305 channels) are used in this study. To simulate CrIS radiances, observations of temperature, moisture, and aerosol profiles are used. The use of a series of meteorological observations opposed to using a meteorological analysis and/or climatology is beneficial for two reasons: perfect coupling between the temperature, moisture, and aerosol profiles is ensured; and the atmosphere rarely reproduces climatology, but rather deviations about a model analysis and/or climatology that can better be represented using observations. Additionally, simulated HIS observations are performed with incoming solar radiance turned off (i.e., nighttime simulations). Nighttime simulations are desired because solar reflectance off dust particles and the surface is poorly modeled, and near-IR wavelengths sensitive to solar radiation are typically not assimilated at present in operational systems. While we will examine these shorter wavelengths here, the signal simulated at these wavelengths is only derived from terrestrial emissions for nighttime simulations.

Since the atmospheric temperature, moisture, and aerosol profiles used to simulate the HIS observations are known, the impact of aerosols on assimilation can be directly determined. To quantify this impact, a series of experiments is performed in which the synthetic HIS observations are provided to the 1DVAR system. For the first-guess atmosphere, the same profiles used to create the HIS observations are used. By enabling and disabling aerosol calculations, a difference in analyzed moisture and temperature fields is quantified, which, as all other parameters remain constant, are uniquely due to aerosol. However, this approach is only valid if the system is able to correctly retrieve the temperature and moisture fields used to create the synthetic HIS observations with aerosol enabled. Thus, as a first step, we verify the ability of the system to perform expectedly with aerosol parameters enabled (i.e., calculate temperature and moisture increments of approximately zero with respect to the "true" atmosphere).

\section{b. Observations}

\section{1) ATMOSPHERIC PROFILES}

Temperature and moisture profiles observed via regular rawinsonde launches from near the Tenerife North Airport (ICAO: GCXO) are used. Due to lack of observations at high altitudes (i.e., above $20 \mathrm{~km}$ MSL) needed to simulate CrIS radiances and perform $1 \mathrm{DVAR}$ assimilation, each profile is merged with a tropical standard atmosphere (McClatchey et al. 1972). For consistency, only radiosonde temperature and moisture are used from the surface to $300 \mathrm{hPa}$ and only standard atmospheric temperature and moisture are used above $100 \mathrm{hPa}$. Between 300 and $100 \mathrm{hPa}$, the profiles were merged using a linear weighting function. As regular rawinsonde launches do not observe ozone concentrations, the standard tropical atmospheric ozone profile is also used. These meteorological profiles are interpolated vertically to the background error covariance matrix levels in the $1 \mathrm{DVAR}$ model linearly by logarithmic pressure. The mean temperature and dewpoint profiles for cases used in this study are shown in Fig. 3. It is important to note that while a standard meteorological profile at high altitudes is a crude approximation, the aerosol bias quantification is limited to the lowest portions of the troposphere. Coupled with the use of synthetic HIS observations, the impact of using a standard meteorological profile at high altitude has an insignificant, if any, influence on bias quantification at the lower altitudes where aerosol loading is typically largest (Yu et al. 2010).

\section{2) MicROPUlSE LIDAR AND SUN PHOTOMETER AEROSOL RETRIEVAL}

MPLNET is a network of micropulse lidars (MPL), often spatially collocated with AERONET sun photometers, to provide information on the vertical distribution of aerosols and clouds (Welton et al. 2001; Campbell et al. 2002). The Tenerife MPLNET site provides a long-term record for Saharan dust advection out over the eastern tropical Atlantic. Specifically, the MPLNET data record at Tenerife goes back to 2005, with the years $2008-09$ and 2011-14 having $>90 \%$ of days recording observations. As such, we have limited our study period to 2008-09 and 2011-14. We further limit our study period to June through November where aerosol profiles are likely to be dominated by dust. The spatially collocated AERONET instrument collects routine daytime measurements of AOD and Ångström exponent (AE) exhibiting $>96 \%$ of days recording observations during our time period. We use the Spectral Deconvolution Algorithm, version 4.1, using version 2 direct-sun AOD inputs level 2.0 AERONET AOD and AE observations [see O'Neill et al. (2008) for retrieval information] for converting version 3 MPLNET level 1 normalized 


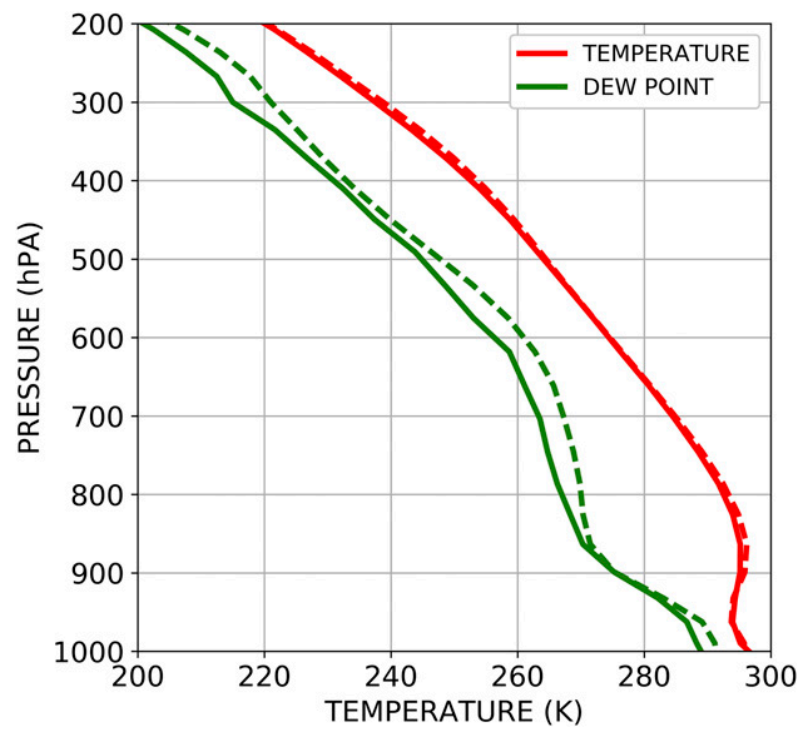

FIG. 3. Mean temperature (red) and dewpoint (green) profiles at Santa Cruz de Tenerife from rawinsonde observations (solid) and MERRA-2 (dashed) bilinearly interpolated to the rawinsonde launch location.

relative backscatter to $523 \mathrm{~nm}$ aerosol extinction coefficient profiles (Welton et al. 2000). Because RTTOV, and thus the modified 1DVAR system, require aerosol number concentration, the $523 \mathrm{~nm}$ aerosol extinction coefficient profiles derived from MPL-AERONET observations are converted to a number concentration profile based upon relationships developed using OPAC, and discussed later. AERONET retrievals of aerosol fine mode fraction (FMF) are also applied for aerosol species modality.

Applying MPLNET normalized relative backscatter coupled with spatial and temporal collocated AERONET AOD, $\mathrm{AE}$, and FMF, $550 \mathrm{~nm}$ total, fine-mode, and coarse-mode aerosol extinction profiles are determined using the inversion method described in Fernald (1984), referred to as the Fernald inversion. As the first step of this approach, the Fernald inversion is performed using the total column AOD from AERONET as the inversion constraint to derive total aerosol extinction profiles similar to that described by Welton et al. (2000). We split each of the aerosol extinction profiles into fineand coarse-mode extinction by multiplying with the FMF from AERONET. Note, since the FMF provided by AERONET is a column-integrated measurement, we assume it does not vary with height when determining aerosol extinction profiles.

Calculation of aerosol extinction profiles using the Fernald inversion is only performed on layers containing aerosol backscatter (i.e., aerosol layers). Aerosol layer detection is performed by determining layers of backscatter between the surface and $10 \mathrm{~km}$ with consistent backscatter above a height-dependent threshold. This height-dependent threshold value is the sum of the Rayleigh molecular backscatter and a noise estimate determined from backscatter at 8-10 km altitude (e.g., Campbell et al. 2008). Since the Rayleigh molecular backscatter is calculated using the rawinsonde observations, the MPL backscatter observations must be collocated temporally with the rawinsonde launches. Additionally, since the Fernald inversion uses the aerosol optical depth as a constraint to retrieve aerosol extinction from the backscatter profile, temporal collocation with AERONET observations is also required. Thus, the study is limited to daytime observations where AERONET, MPL, and rawinsonde observations are possible. Note, we assume the impact of solar contamination on the MPL backscatter profile and our retrieved aerosol extinction profiles is negligible. Thus, we assume turning solar off in our simulations is not likely to be significantly biased due to the use of daytime observations.

Temporal collocation with the rawinsonde launch is done individually for both the MPL and AERONET observations. For AERONET, the closest retrieval in time to the rawinsonde launch (limited to $\pm 30 \mathrm{~min}$ ) is used. For MPL, all 1-min normalized relative backscatter profiles within \pm 10 min of the rawinsonde launch, for a maximum of 20 profiles, are cloud screened using a gradient threshold method (similar to Clothiaux et al. 1998) and averaged to a single mean normalized relative backscatter profile collocated temporally with the rawinsonde launch. Any collocated mean backscatter profiles averaged from less than eight of the possible twenty individual backscatter profiles are removed from the dataset as they represent increased noise and/or cloud contamination. The mean backscatter profile within determined aerosol layer(s) is then converted to total, fine-mode, and coarse-mode aerosol extinction using the aforementioned Fernald inversion constrained by the spatial and temporally collocated AERONET observations. To QC the retrievals, we only examine profiles with the (Fernald inversion retrieved) $550 \mathrm{~nm}$ extinction-to (MPL observed) $-532 \mathrm{~nm}$ backscatter ratios (i.e., lidar ratio; Ackermann 1998) that fall between 10 and 70 sr (e.g., Campbell et al. 2002). Note, while the lidar ratio will be very slightly offset due to the backscatter being at $523 \mathrm{~nm}$ and the extinction being at $550 \mathrm{~nm}$, these differences will be very small and negligible for QCing purposes. This lidar ratio threshold helps ensure the relative stability of the Fernald inversion. It is important to note, that while this threshold should contain all dust-dominated aerosol profiles, it is noninclusive with respect to species and other nondust aerosol types may be present. To better limit the study to only likely dust aerosol retrievals, we only use retrievals from June through November.

The study period of June-November is chosen to correspond with the furthest north extent of the African easterly jet (Grist 2002). The African easterly jet and African easterly waves are important in the advection of dust from the Sahara to the eastern tropical Atlantic (Jones et al. 2003). Further, JuneNovember corresponds with the Atlantic Hurricane Season, where weather forecasts over the tropical Atlantic become important for tropical cyclone forecasting. Thus, this season represents a period when large quantities of data are both needed for accurate tropical cyclone forecasts ( $\mathrm{Li}$ and $\mathrm{Liu}$ 2009) and are most likely to be limited and/or contaminated by dust aerosol.

In total, 210 profiles were retrieved from the Tenerife ground datasets for the study period of June-November 2008 to 2014 (note, no data are available for 2010 for these months). Of the 210 cases, 113 were removed due to quality checks, 

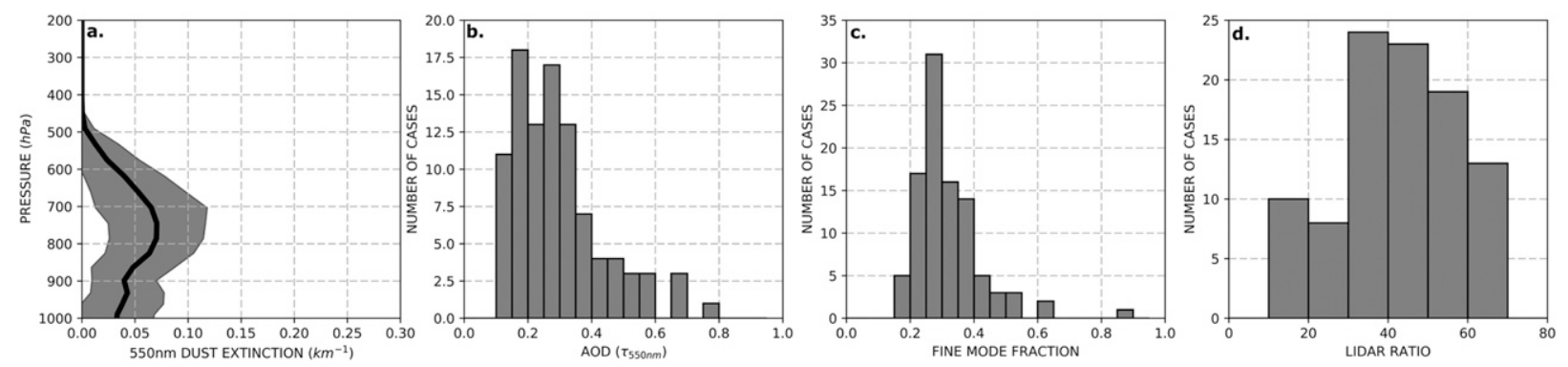

FIG. 4. (a) Mean dust extinction profile with \pm 1 standard deviation shaded. Histograms of (b) aerosol optical depth, (c) fine mode fraction, and (d) extinction-to-backscatter ratio (lidar ratio) from retrieved MPL dust profiles.

including hand checks for failed retrievals, requirements for a minimum eight MPL backscatter profiles, and lidar ratio thresholding. Thus, the remaining 97 QC profiles are examined in this study. Each of the 97 cases are processed in the 1DVAR system individually and statistics for these results are presented in section 3 .

Shown in Fig. 4 is the mean dust extinction profile over the 97 cases, and histograms of the corresponding AOD, FMF, and extinction-to-backscatter ratio (lidar ratio). Despite the proximity of the Tenerife site to the Saharan dust belt, the AOD $(550 \mathrm{~nm})$ is relatively low (mean AOD of 0.30 ) with only 10 cases $(10.9 \%)$ at or above 0.5 AOD. Figure 4 also indicates those dust profiles are dominated by coarse mode particles, with only $6(6.5 \%)$ profiles having FMF at or above 0.5 . The majority of cases exhibit lidar ratios between 30 and $60 \mathrm{sr}$, consistent with, but not exclusive to, other lidar dust observations (Müller et al. 2007). We reiterate though, the uncertainty due to misclassification of nondust aerosol profiles as dust will be minimized through the use of synthetic HIS observations.

As previously discussed, when aerosol parameters are enabled, the RTTOV system requires aerosol presence to be depicted in units of aerosol number concentration. Since aerosol extinction profiles are the derived parameter from MPL observations, conversion from extinction to number concentration is necessary. Thus, the OPAC database is used to construct relationships between extinction and RTTOV-required number concentration [Eqs. (1)-(3)]. Note, the aerosol model in RTTOV is developed using the OPAC database, and therefore these relationships are inherently consistent. The equations for converting fine and coarse-mode extinction to nucleating, accumulating, and coarse-mode dust are

$$
\begin{aligned}
& n_{\mathrm{nuc}}=\left(\beta_{\mathrm{ext}, f}\right) \times 14005.55 \mathrm{~km} \mathrm{~cm}^{-3}, \\
& n_{\mathrm{acc}}=\left(\beta_{\mathrm{ext}, f}\right) \times 320.41 \mathrm{~km} \mathrm{~cm}^{-3}, \quad \text { and } \\
& n_{\mathrm{coa}}=\left(\beta_{\mathrm{ext}, c}\right) \times 12.82 \mathrm{~km} \mathrm{~cm}^{-3},
\end{aligned}
$$

where $n$ is the number concentration in $\mathrm{cm}^{-3}, \beta_{\text {ext,f }}$ is the $550 \mathrm{~nm}$ fine-mode extinction coefficient in $\mathrm{km}^{-1}$, and $\beta_{\text {ext,c }}$ is the $550 \mathrm{~nm}$ coarse-mode extinction coefficient in $\mathrm{km}^{-1}$. Note, while the OPAC database has a transported-mode dust, this aerosol type is only used in OPAC's Antarctic-type atmosphere aerosol mixture. As indicated in Eqs. (1)-(3) fine-mode aerosol extinction is converted to a combination of both nucleating and accumulating-mode dust aerosols. To split the fine-mode extinction into number concentration for these two modes, we constrain the number ratio between the nucleating and accumulating mode aerosols to be consistent with the OPAC desert atmosphere aerosol mixture (Hess et al. 1998). Note, while the MPL-AERONET extinction profiles are determined at $523 \mathrm{~nm}$, these profiles are converted to $550 \mathrm{~nm}$ for use in Eqs. (1)-(3) using the AERONET-retrieved AE.

With known temperature, moisture, ozone, and aerosol number concentration profiles, synthetic CrIS observations are calculated using RTTOV. For testing, as expected, if we provide the 1DVAR system with the same observations used to derive the synthetic CrIS observations, the resulting innovations are $\sim 0 \mathrm{~K}$ if aerosol parameters are enabled, with slight deviations on the order of $10^{-2} \mathrm{~K}$ due to truncation of input HIS radiances causing small brightness temperature differences between the background (as calculated by the forward model) and observation. While obvious, such results indicate that the method of including dust aerosol in the forward model calculations is sufficient to retrieve the underlying temperature and moisture profiles independent of dust-contaminated HIS radiance observations when the correct dust profile is provided to the forward model (i.e., the system is performed as expected). Note that zero innovations do not mean observations are perfect with no error, as observational errors are defined by the error covariance matrix developed for the CrIS aboard Suomi NPP, available on the NWP-SAF website (Hilton 2016). Note, CrIS observations have errors due to several intrinsic and extrinsic sources (Center for Satellite Applications and Research 2018). Additionally, implicit error/uncertainty in the synthetic observations is already accounted for by the error variance terms in the observational error covariance matrix, and thus no additional noise is added to the synthetic observations. Again, by enabling the aerosol parameters in the 1DVAR system, we expect near zero innovations and increments for the purpose of sanity check of the system. By disabling the aerosol parameters in the 1DVAR system, we expect innovations to be nonzero. In this case, increments are modulated by background and observational error matrices. Ideally the uncertainty of the forward model would be included in the observational error covariance matrix. For simplicity, we assume the uncertainty in the forward model is negligible. Aerosol biases are determined by simply taking the difference in analyzed temperature and moisture 
profiles between enabling and disabling the aerosol parameters in the 1DVAR system.

\section{c. $M E R R A-2$}

The experiment outlined above provides the first-order estimation of aerosol impact with the use of observed atmospheric profiles. In operational practice, however, modeled atmospheric profiles, which are typically less accurate than observed profiles, are used. Thus, the next step is to reexamine the impacts and explore the feasibility of decreasing operational analysis error by providing observed dust aerosol profiles to the coupled 1DVAR system with the first guess coming from modeled temperature and moisture profiles. Here, we use MERRA-2 6-hourly instantaneous analysis temperature and moisture fields at $5 / 8^{\circ} \times 1 / 2^{\circ}$ resolution, bilinearly interpolated to the Santa Cruz rawinsonde launch site as the first-guess atmospheric profiles.

The mean MERRA-2 temperature and moisture profiles for the 97 cases introduced above are shown in Fig. 3 alongside the rawinsonde observed temperature and moisture profiles. Slight differences are evident in the MERRA-2 and observed temperature profiles, namely, below $700 \mathrm{hPa}$ and above $500 \mathrm{hPa}$, possibly due to interpolation to a point observation. Unlike the temperature field, there is a distinct and consistent dewpoint bias of $\sim 5 \mathrm{~K}$ above $800 \mathrm{hPa}$, with smaller moist biases below $800 \mathrm{hPa}$. While reanalysis profiles are likely to be closer to truth than an operational first-guess atmosphere based on a previous forecast, the differences evident between the reanalysis and the observations suggest analysis can be used as a proxy for an imperfect first-guess background like that used in operations. Note, we also assume the rawinsonde observations represent the real atmosphere, even though there are also small inherent errors within these observations (e.g., Mapes et al. 2003). Since synthetic HIS radiances are constructed from rawinsonde observations in this study, temperature and moisture profiles from these observations can be considered "truth" in this context.

\section{Results}

\section{a. MPL assessment}

The dust-induced radiance cold bias for the 97 cases, determined from the difference between the brightness temperatures calculated from the rawinsonde observations with aerosol disabled and the synthetic CrIS brightness temperatures, is shown in Fig. 5. The innovations, or again the observed minus that simulated from the background, shown in Fig. 5, exhibit a peak near $0.65 \mathrm{~K}$ for the dataset with mean AOD of 0.3. There are many differences which we will detail; however, the spectral shape of the innovations between Fig. 5 and the results in P04 are strikingly consistent with those for this study, which is encouraging.

This aerosol-induced innovation is significantly lower than what should be expected from the results published in P04 ( $5 \mathrm{~K}$ for $0.75 \mathrm{AOD}$ ). There are several possible reasons for discrepancies between innovations found here and those presented in P04. First, P04 assume all dust aerosols are located within a single model layer while here observed profiles with

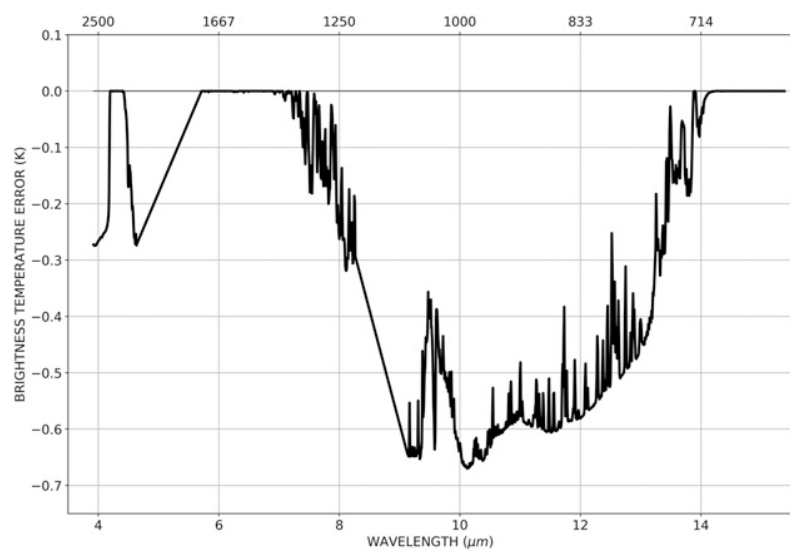

FIG. 5. Mean brightness temperature innovation resulting from assimilating dust-biased radiances with mean AOD of $0.30\left(\tau_{550}\right)$.

dust diffused throughout the lowest 5 to $6 \mathrm{~km}$ above ground level are used. Further, P04 mainly examined dust in the transported-mode OPAC classification. In contrast to P04, we use a combination of fine- and coarse-mode dust that is consistent with the desert-type aerosol profile in OPAC. P04 used a static, climatological meteorological profile, while here we use atmospheric profiles from rawinsonde observations, which may impact the resulting innovations. Additionally, P04 focused on simulations for AIRS which would bring discrepancies due to different spectral sampling characteristics between the sensors (Tobin et al. 2013); however, this likely contributes very small differences and again we note that the spectral signatures appear consistent between AIRS and CrIS. Finally, slight differences may be due to P04 using a modified version of the Automatized Atmospheric Absorption Atlas (4A; Scott and Chedin 1981); whereas we use RTTOV for our forward calculations. Thus, while discrepancies in innovation likely exist due to differences in experimental designs, both studies demonstrate impacts of the same order of magnitude and spectral shape.

As expected, when aerosol is enabled, the analyzed profiles derived from the 1DVAR system match the observed temperature and moisture profiles for each case. This confirms that the $1 \mathrm{DVAR}$ is properly configured, while also inferring that HIS assimilation in dusty scenes is feasible, given an accurate dust profile and highly accurate background atmosphere. Figure 6 shows the temperature and dewpoint biases associated with unaccounted dust aerosols in HIS retrievals. Both temperature and dewpoint biases are evident from the surface to near $300 \mathrm{hPa}$. Analysis temperature bias peaks near $825 \mathrm{hPa}$. The dewpoint bias peaks near $950 \mathrm{hPa}$, but has a secondary peak associated with an area of large variance at $750 \mathrm{hPa}$.

Considering the dust layer shown in Fig. 4 extending from the surface to $500 \mathrm{hPa}$ and peaking near $700 \mathrm{hPa}$, the analysis bias peaks are well within the aerosol layer, but consistently below the level of peak extinction. Relatively high biases also extend above the top of the aerosol layer by approximately $200 \mathrm{hPa}$ suggesting the impact on analyses are not solely constrained to the aerosol layer, but expand vertically, possibly due to some bands exhibiting Jacobian functions with sensitivity 

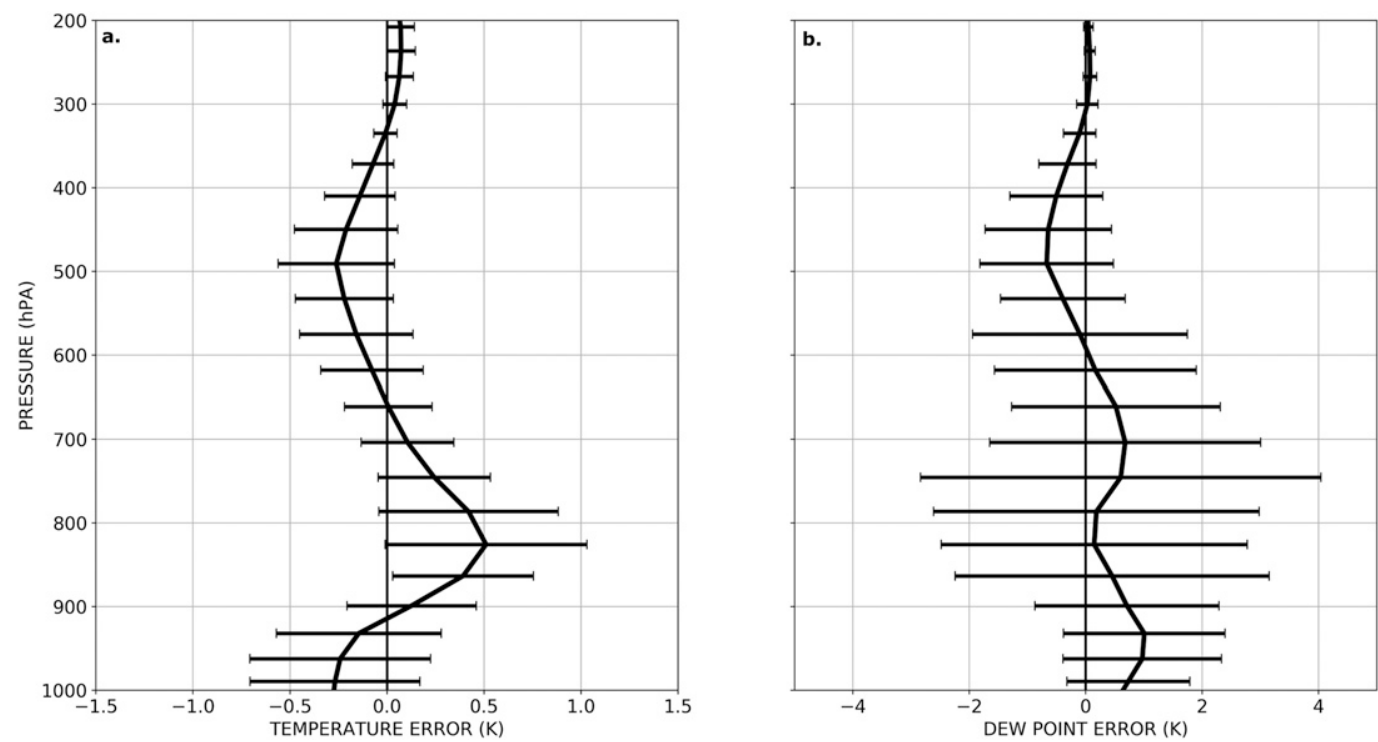

FIG. 6. Mean and \pm 1 standard deviation (a) temperature and (b) dewpoint analysis difference compared to rawinsonde observations when aerosol is disabled.

both within, and above, the aerosol layer. While analyzed temperature bias peaks around $0.5 \mathrm{~K}$, dewpoint bias peaks above $1 \mathrm{~K}$ with large standard deviations. Note that while these bias estimates are related to the background error statistics used, the impacts are nonnegligible, even significant, given the relatively low AOD of the retrievals.

Given that the mean aerosol loading in the MPLNET data is relatively low compared with nearby tropical Atlantic regions within the Saharan dust belt (e.g., Alfaro-Contreras et al. 2017), dust-induced biases may be even higher in these regions. Additionally, because these regions lack in situ observations, analyses are more likely to exhibit higher dependency on HIS radiance assimilation possibly resulting in even larger impacts. Note, even in the Tenerife region, the mean MPLNET-AERONET aerosol loading is low compared to that found in moderate or extreme dust events in the region (e.g., Colarco et al. 2003). While such moderate/extreme dust events are less frequent, Fig. 2 suggests assimilation of radiances contaminated by AODs $>1.0$ do occur on submonthly time scales. Thus, we estimate the impact of assimilating dust-biased radiances at higher AODs by determining the relationships between AOD and peak brightness temperature bias $\left(\mathrm{BT}_{\text {bias }}\right)$ and various other parameters, including peak temperature and dewpoint biases. These relationships are shown in Fig. 7. Consistent with the findings of P04, a strong, linear relationship between AOD and peak brightness temperature, estimated using the TheilSen regression (Theil 1950a,b,c), is found ( $r=0.756$; $\mathrm{BT}_{\text {bias }}=$ $2.608 \times$ AOD - 0.141). The Theil-Sen regression is performed as this method is less susceptible to outliers (Theil 1950a,b,c). While the slope of this relationship is less than half the relationship shown in P04 (see Fig. 1 in P04), differences are likely due to the disparities in methodology explained above. Similarly, relationships derived comparing AOD and analyzed temperature and dewpoint indicate a unit change in AOD could introduce temperature change of $2.4 \mathrm{~K}\left(T_{\text {bias }}=2.357 \times \mathrm{AOD}-0.200\right.$; $r=0.759)$ and dewpoint change of $8.6 \mathrm{~K}\left(T_{D_{\text {bias }}}=8.554 \times\right.$ AOD $0.848 ; r=0.688)$. Note, while these values are significant given the mean AODs of $0.25-0.50\left(\tau_{550}\right)$ observed in the tropical Atlantic (Alfaro-Contreras et al. 2017), aerosol "events" often exceed AOD of 1 (Colarco et al. 2003). Thus, while impacts may be smaller, yet not negligible, in a climatological sense, biases may vary significantly in shorter time spans, which may influence short and medium range forecasting and associated applications (i.e., SST retrievals) if they are not accounted for.

Also, shown in Fig. 6, are the relationships between peak brightness temperature bias and analyzed temperature and dewpoint bias. Strong correlations between peak brightness temperature bias and analyzed temperature $(r=0.957)$ and dewpoint bias $(r=0.918)$ are found. While these correlations are higher than those found for AOD, this is not unexpected since increments to the temperature and dewpoint profiles are a function of brightness temperature innovations. These relationships show a brightness temperature innovation of $1 \mathrm{~K}$ can introduce nearly $1 \mathrm{~K}$ temperature biases $\left(T_{\text {bias }}=0.887 \times \Delta \mathrm{BT}-0.015\right)$ and nearly $4 \mathrm{~K}$ dewpoint biases $\left(T_{D_{\text {bias }}}=3.452 \times \Delta \mathrm{BT}-0.263\right)$. The results here show that any unscreened aerosol-biased radiances may cause large biases on model analyses. Considering the presence of unscreened aerosols in other infrared radiometric products, and the suggestion in Fig. 2 that HIS assimilation is not immune to this problem, the community must be aware of the high possibility of this previously unrealized source of analysis bias.

\section{b. MERRA-2 assessment}

Here, similar analyses as shown in section 3 a are implemented but with the use of modeled atmospheric temperature and moisture profiles instead of rawinsonde observations. The mean temperature and dewpoint analysis biases with aerosol enabled and disabled, are shown alongside the mean MERRA-2 background biases in Fig. 8. Here, bias is defined as deviations 

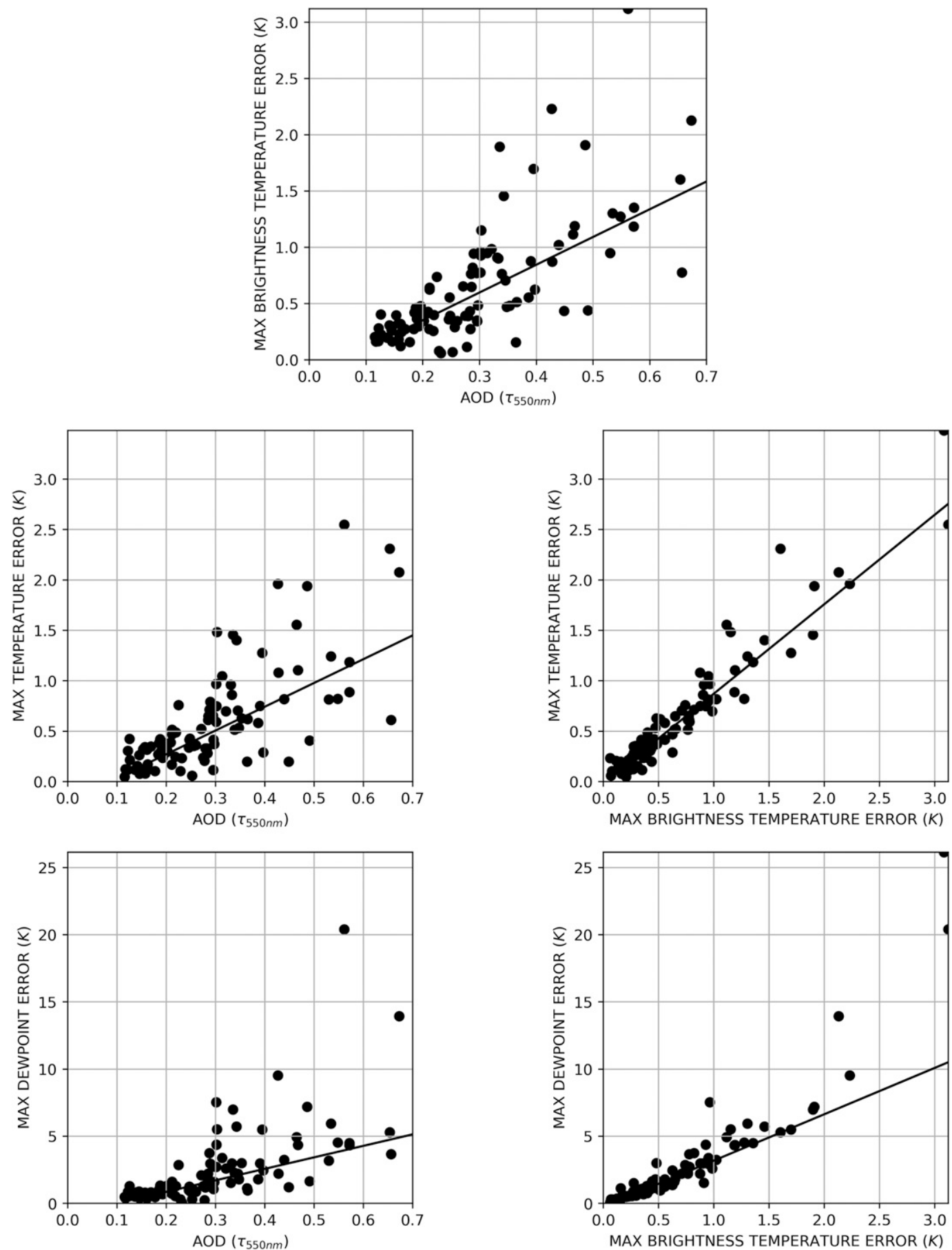

FIG. 7. Relationships with linear regression indicated for (a) aerosol optical depth vs maximum brightness temperature bias, (b) aerosol optical depth vs maximum tropospheric analyzed temperature bias, (c) aerosol optical depth vs maximum tropospheric analyzed dewpoint bias, (d) maximum brightness temperature bias vs maximum tropospheric analyzed temperature bias, and (e) maximum brightness temperature bias vs maximum tropospheric analyzed dewpoint bias.

from rawinsonde observations used to create the synthetic HIS radiances. As stated earlier, the mean MERRA-2 profile exhibits significant moist biases throughout the troposphere compared with rawinsonde observations. While temperature biases also exist, these are on the order of $1 \mathrm{~K}$ compared to the 3-6 K dewpoint biases. Interestingly, even when aerosol is disabled, assimilating the synthetic observations almost always results in a more accurate analysis by 

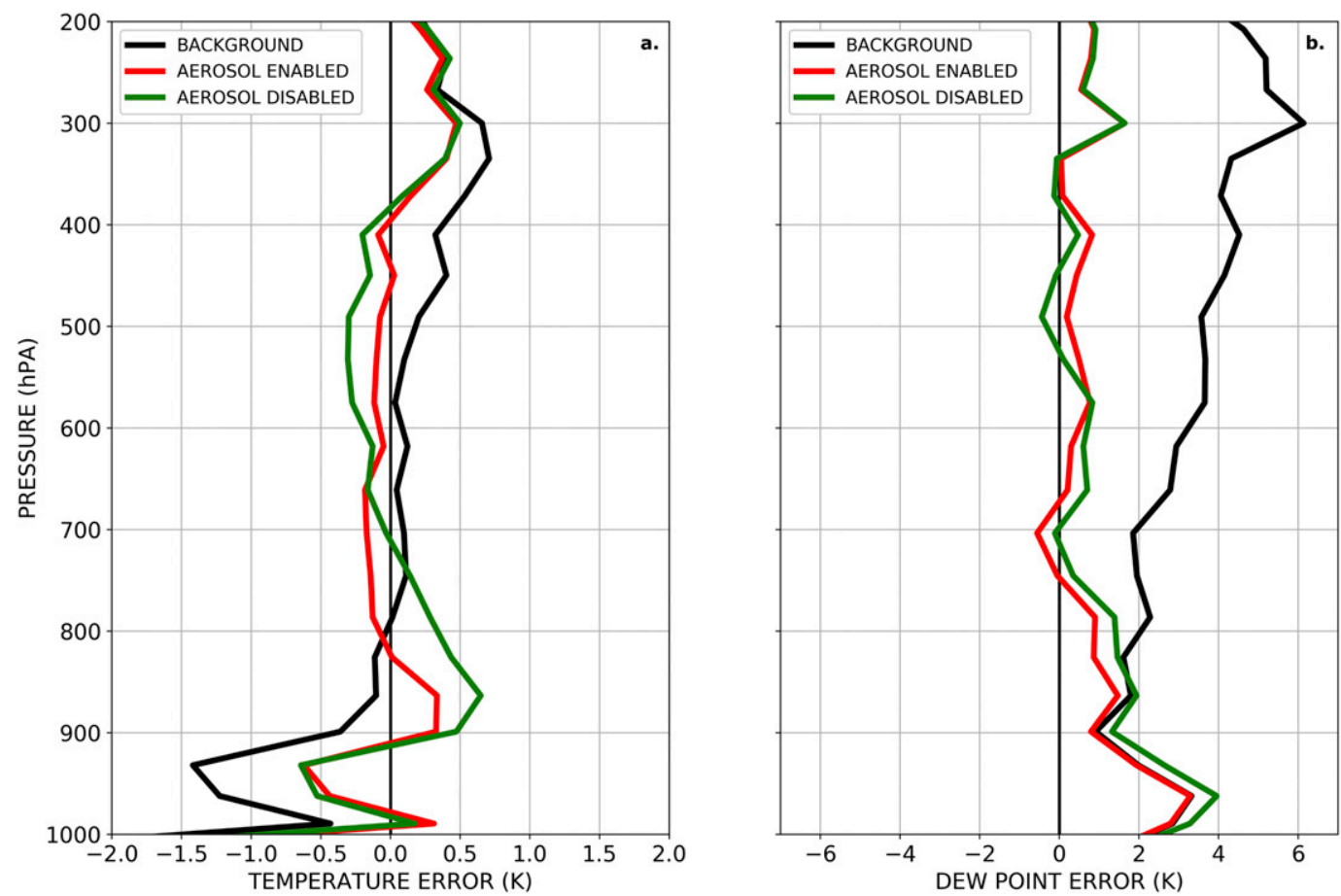

FIG. 8. The difference between the mean rawinsonde (a) temperature and (b) dewpoint profiles and mean, bilinearly interpolated MERRA-2 used as the background atmosphere (black), mean analyzed profiles with aerosol enabled (red), and mean analyzed profiles with aerosol disabled (green).

approximately $0.25 \mathrm{~K}$ and $2-3 \mathrm{~K}$ for temperature and dewpoint, respectively.

Both the temperature and dewpoint profiles show increases in bias compared with the background. For dewpoint, between the surface and $900 \mathrm{hPa}$ the analysis is more biased than the background by approximately $1 \mathrm{~K}$. For temperature, between 900 and $750 \mathrm{hPa}$ the analysis is more biased by approximately $0.25 \mathrm{~K}$. More encouraging, when aerosol is enabled, despite the low average aerosol loading (mean AOD of 0.30), the analyzed temperature and dewpoint profiles were even more accurate, resulting in 0.5 and $1 \mathrm{~K}$ maximum temperature and dewpoint bias reductions, respectively, compared to the aerosol-disabled analyses. This experiment demonstrates that decoupling of the aerosol impact is likely achievable in an operational setting and, thus, there is a need for aerosol information in such a setting where dust aerosols are likely present.

\section{Conclusions and discussion}

In this study, assimilation of aerosol-impacted Hyperspectral Infrared Sounder (HIS) observations is shown to be significant. The impacts of assimilating dust-contaminated HIS radiances on temperature and moisture analyses are investigated, using a one-dimensional variational (1DVAR) assimilation system that has been modified to enable aerosol calculations during forward model calculations and ground-based monitoring of dusty atmospheric column conditions. A total of 97 collocated aerosol extinction profiles retrieved from combined Micropulse Lidar Network (MPLNET) and Aerosol Robotic Network
(AERONET) observations and temperature and humidity profiles measured by rawinsonde launch over Santa Cruz de Tenerife for the study period of 2008-14 were used for aerosol and atmospheric states in the 1DVAR system.

We assess the impact of dust aerosol (mean dust aerosol AOD of 0.30 at $550 \mathrm{~nm}$ ) by accounting for the aerosol in the forward model prior HIS data assimilation, using MPLNET profiles and radiosondes launched at the Santa Cruz de Tenerife, Spain, location. Contrasting the results to that of a nonaerosol run which uses the same a priori, we find mean tropospheric biases above 0.5 and $1.0 \mathrm{~K}$ for temperature and dewpoint, respectively. Given that the mean aerosol loading in the MPLNET data for this location is lower than that found in moderate or extreme dust events, we estimate the impact of assimilating dust-biased radiances at higher AODs by using Theil-Sen regression. By quantifying the retrieved bias as a function of dust AOD, we find a $2.4 \mathrm{~K}$ peak bias in temperature, and a $8.6 \mathrm{~K}$ peak bias in dewpoint per unit AOD (at $550 \mathrm{~nm}$ ) contamination for a dust plume extending to $\sim 700 \mathrm{hPa}$. Relationships between AOD and expected peak temperature bias suggest assimilation of aerosol plumes exhibiting $\mathrm{AOD} \geq 0.30$ induce temperature bias above the expected uncertainty of $\sim 0.4 \mathrm{~K}$. Given that $16.2 \%$ of NAVGEM assimilated HIS observations exhibit AODs above this threshold, aerosol induced bias is likely frequent and should not be ignored. Additionally, with impacts to moisture analysis being much larger than those of temperature, aerosol contamination may be a contributing factor to the relatively high moisture uncertainties present in NWP. Interestingly, this AOD $\geq 0.30$ threshold 
should correspond to a brightness temperature innovation of above the $0.5 \mathrm{~K}$ threshold used for cloud screening. As such, it appears that the current screening methods for cloud are insufficient to screen aerosol. This may be due to the more diffuse aerosol imparting a lower gradient in innovations than that of cloud. That said, possible upstream assimilation may have previously biased the background resulting in lower innovations, likely compounding issues. The suspected failure of cloud screening methods to identify and screen aerosols should be a focus of future studies.

A second experiment is performed in which the background profile is changed to a bilinearly interpolated MERRA-2. This experiment is conducted to simulate the operational practice of using modeled background profiles in the assimilation process. Interestingly, when assimilating dust-loaded HIS data, even without correcting for the dust contamination, bias reductions compared to the background are observed in temperature and moisture analyses. While much of the profile experiences bias reductions, there exist analyses worse than background found in both moisture and temperature, confined to the aerosol layer. By accounting for dust contamination in the assimilation process, an incremental reduction in bias compared to not correcting for dust is observed in both the temperature and moisture analyses. More importantly, unlike when dust contamination is ignored, nowhere in the profile is the analyzed temperature or moisture more biased than the background, suggesting correcting dust-contaminated HIS data in assimilation could be realistically applied for numerical weather prediction. Additionally, these results suggest that the high current expected moisture uncertainties of $\sim 20 \%$ could possibly be lowered.

Our results are based upon observed aerosol profiles from combined MPLNET-AERONET retrievals. It is recognized that the use of such dataset may not be practical in an operational setting. To mitigate the lack of global high resolution vertical aerosol observations, accurate aerosol profiles from aerosol prediction models (e.g., NAAPS or MERRA-2) may prove to be sufficient, though this will have to be investigated in detail. Additionally, future satellite missions could include coincident aerosol measurements (e.g., from lidar) to provide a collocated aerosol profiles with radiance observations. While this study was limited to the examination of dust aerosols, the system design allows for investigation of other aerosol types. Also, while the focus of this study was HIS radiance assimilation, the method of including aerosol profiles during assimilation could be extended to any radiance assimilation. Additionally, similar methodology could, in theory, be applied for unscreened thin cirrus clouds that are likely to have similar or even more significant impacts to analyzed temperature and moisture fields and the surface analysis such as surface temperature.

Acknowledgments. This study is supported by the NASA ROSES Science of Terra and Aqua program (T. Lee; 80HQTR18T0085). J. Marquis and J. Zhang are also supported by NASA Grant NNX17AG52G and the Office of Naval Research Grant N00014-16-1-2040. M. Oyola and B. Ruston are also supported by Office of Naval Research Grant N0001419-WX-01593. The MPLNET project is funded by the NASA
Radiation Sciences Program and Earth Observing System. MPLNET observations at the Santa Cruz de Tenerife site are supported by the INTA Grant IGE03004.

\section{REFERENCES}

Ackermann, J., 1998: The extinction-to-backscatter ratio of tropospheric aerosol: A numerical study. J. Atmos. Oceanic Technol., 15, 1043-1050, https://doi.org/10.1175/1520-0426(1998)015<1043: TETBRO $>2.0 . \mathrm{CO} ; 2$.

Alfaro-Contreras, R., J. Zhang, J. S. Reid, and S. Christopher, 2017: A study of 15-year aerosol optical thickness and direct shortwave aerosol radiative effect trends using MODIS, MISR, CALIOP and CERES. Atmos. Chem. Phys., 17, 13 849-13868, https://doi.org/10.5194/acp-17-13849-2017.

Aumann, H. H., and R. J. Pagano, 1994: Atmospheric Infrared Sounder on the Earth observing system. Opt. Eng., 33, 776785, https://doi.org/10.1117/12.159325.

Bloom, H., 2001: The Cross-Track Infrared Sounder (CrIS): A sensor for operational meteorological remote sensing. Proc. IEEE 2001 Int. Geosci. Remote Sensing Symp., Sydney, Australia, IEEE, https://doi.org/10.1109/IGARSS.2001.976838.

Bogdanoff, A. S., D. L. Westphal, J. R. Campbell, J. A. Cummings, E. J. Hyer, J. S. Reid, and C. A. Clayson, 2015: Sensitivity of infrared sea surface temperature retrievals to the vertical distribution of airborne dust aerosol. Remote Sens. Environ., 159, 1-13, https://doi.org/10.1016/j.rse.2014.12.002.

Campbell, J. R., D. L. Hlavka, E. J. Welton, C. J. Flynn, D. D. Turner, J. D. Spinhirne, V. S. Scott, and I. H. Hwang, 2002: Full-time, eye-safe cloud and aerosol lidar observation at Atmospheric Radiation Measurement program sites: Instruments and data processing. J. Atmos. Oceanic Technol., 19, 431-442, https://doi.org/10.1175/1520-0426(2002)019<0431:FTESCA $>$ 2.0.CO;2.

-, K. Sassen, and E. J. Welton, 2008: Elevated cloud and aerosol layer retrievals from micropulse lidar signal profiles. J. Atmos. Oceanic Technol., 25, 685-700, https://doi.org/ 10.1175/2007JTECHA1034.1.

Campbell, W. F., E. A. Satterfield, B. Ruston, and N. L. Baker, 2017: Accounting for correlated observation error in a dualformulation 4D variational data assimilation system. Mon. Wea. Rev., 145, 1019-1032, https://doi.org/10.1175/MWR-D-16-0240.1.

Center for Satellite Applications and Research, 2018: Joint Polar Satellite System (JPSS) Cross Track Infrared Sounder (CrIS) sensor data records (SDR) Algorithm Theoretical Basis Document (ATBD) for full spectral resolution. NOAA STAR Algorithm Theoretical Basis Doc., 221 pp., https://www.star.nesdis.noaa.gov/ jpss/documents/ATBD/D0001-M01-S01-002_JPSS_ATBD_ CRIS-SDR_fsr_20180614.pdf.

Chahine, M. T., and Coauthors, 2006: AIRS: Improving weather forecasting and providing new data on greenhouse gases. Bull. Amer. Meteor. Soc., 87, 911-926, https://doi.org/ 10.1175/BAMS-87-7-911.

Clothiaux, E. E., G. G. Mace, T. P. Ackerman, T. J. Kane, J. D. Spinhirne, and V. S. Scott, 1998: An automated algorithm for detection of hydrometeor returns in micropulse lidar data. J. Atmos. Oceanic Technol., 15, 1035-1042, https://doi.org/ 10.1175/1520-0426(1998)015<1035:AAAFDO > 2.0.CO;2.

Colarco, P. R., and Coauthors, 2003: Saharan dust transport to the Caribbean during PRIDE: 2. Transport, vertical profiles, and deposition in simulations of in situ and remote sensing observations. J. Geophys. Res., 108, 8590, https://doi.org/10.1029/ 2002JD002659. 
Eresmaa, R., 2014: Imager-assisted cloud detection for assimilation of Infrared Atmospheric Sounding Interferometer radiances. Quart. J. Roy. Meteor. Soc., 140, 2342-2352, https://doi.org/ 10.1002/qj.2304.

Fernald, F. G., 1984: Analysis of atmospheric lidar observations: Some comments. Appl. Opt., 23, 652-653, https://doi.org/10.1364/ AO.23.000652.

Gelaro, R., and Coauthors, 2017: The Modern-Era Retrospective Analysis for Research and Applications, version 2 (MERRA-2). J. Climate, 30, 5419-5454, https://doi.org/10.1175/JCLI-D-160758.1.

Goldberg, M. D., H. Kilcoyne, H. Cikanek, and A. Mehta, 2013: Joint Polar Satellite System: The United States next generation civilian polar-orbiting environmental satellite system. J. Geophys. Res. Atmos., 118, $13463-13475$, https://doi.org/ 10.1002/2013JD020389.

Grist, J. P., 2002: Easterly waves over Africa. Part I: The seasonal cycle and contrasts between wet and dry years. Mon. Wea. Rev., 130, 197-211, https://doi.org/10.1175/1520-0493(2002) 130<0197:EWOAPI $>2.0$. CO;2.

Guidard, V., N. Fourrié, P. Brousseau, and F. Rabier, 2011: Impact of IASI assimilation at global and convective scales and challenges for the assimilation of cloudy scenes. Quart. J. Roy. Meteor. Soc., 137, 1975-1987, https://doi.org/10.1002/qj.928.

Hess, M., P. Koepke, and I. Schult, 1998: Optical properties of aerosols and clouds: The software package OPAC. Bull. Amer. Meteor. Soc., 79, 831-844, https://doi.org/10.1175/15200477(1998)079<0831:OPOAAC > 2.0.CO;2.

Hilton, F., 2016: NWPSAF 1D-VAR user manual: Software version 1.1.1. EUMETSAT NWP-SAF Rep. NWPSAF-MO-UD-032, 24 pp., https://www.nwpsaf.eu/site/software/1d-var/documentation.

_- and Coauthors, 2012: Hyperspectral Earth observation from IASI: Five years of accomplishments. Bull. Amer. Meteor. Soc., 93, 347-370, https://doi.org/10.1175/BAMS-D-11-00027.1.

Hogan, T. F., and Coauthors, 2014: The Navy Global Environmental Model. Oceanography, 27 (3), 116-125, https://doi.org/10.5670/ oceanog.2014.73.

Holben, B. N., and Coauthors, 1998: AERONET-A federated instrument network and data archive for aerosol characterization. Remote Sens. Environ., 66, 1-16, https://doi.org/ 10.1016/S0034-4257(98)00031-5.

Jones, C., N. Mahowald, and C. Luo, 2003: The role of easterly waves on African desert dust transport. J. Climate, 16, 3617-3628, https:// doi.org/10.1175/1520-0442(2003)016<3617:TROEWO>2.0.CO;2.

Langland, R. H., and N. L. Baker, 2004: Estimation of observation impact using the NRL atmospheric variational data assimilation adjoint system. Tellus, 56A, 189-201, https://doi.org/ 10.3402/tellusa.v56i3.14413.

Le Marshall, J., and Coauthors, 2005: Impact of Atmospheric Infrared Sounder observations on weather forecasts. Eos, Trans. Amer. Geophys. Union, 86, 109-116, https://doi.org/ 10.1029/2005EO110002.

— casting with AIRS. Bull. Amer. Meteor. Soc., 87, 891-895, https://doi.org/10.1175/BAMS-87-7-891.

Li, J., and H. Liu, 2009: Improved hurricane track and intensity forecast using single field-of-view advanced IR sounding measurements. Geophys. Res. Lett., 36, L11813, https://doi.org/ 10.1029/2009GL038285.

Lynch, P., and Coauthors, 2016: An 11-year global gridded aerosol optical thickness reanalysis (v1.0) for atmospheric and climate sciences. Geosci. Model Dev., 9, 1489-1522, https://doi.org/ 10.5194/gmd-9-1489-2016.
Mapes, B. E., P. E. Ciesielski, and R. H. Johnson, 2003: Sampling errors in rawinsonde-array budgets. J. Atmos. Sci., 60, 2697-2714, https://doi.org/10.1175/1520-0469(2003)060<2697:SEIRB > 2.0.CO;2.

Marquis, J. W., A. S. Bogdanoff, J. R. Campbell, J. A. Cummings, D. L. Westphal, N. J. Smith, and J. Zhang, 2017: Estimating infrared radiometric satellite sea surface temperature retrieval cold biases in the tropics due to unscreened optically thin cirrus clouds. J. Atmos. Oceanic Technol., 34, 355-373, https:// doi.org/10.1175/JTECH-D-15-0226.1.

McClatchey, R. A., R. W. Fenn, J. A. Selby, F. E. Volz, and J. S. Garing, 1972: Optical properties of the atmosphere. DTIC Doc., 113 pp.

McNally, A. P., and P. D. Watts, 2003: A cloud detection algorithm for high-spectral-resolution infrared sounders. Quart. J. Roy. Meteor. Soc., 129, 3411-3423, https://doi.org/10.1256/qj.02.208.

Mecikalski, J. R., and K. M. Bedka, 2006: Forecasting convective initiation by monitoring the evolution of moving cumulus in daytime GOES imagery. Mon. Wea. Rev., 134, 49-78, https:// doi.org/10.1175/MWR3062.1.

Menzel, W. P., T. J. Schmit, P. Zhang, and J. Li, 2018: Satellitebased Atmospheric Infrared Sounder development and applications. Bull. Amer. Meteor. Soc., 99, 583-603, https://doi.org/ 10.1175/BAMS-D-16-0293.1.

Merchant, C. J., A. R. Harris, M. J. Murray, and A. M. Závody, 1999: Toward the elimination of bias in satellite retrievals of sea surface temperature: 1 . Theory, modeling and interalgorithm comparison. J. Geophys. Res., 104, 23 565-23 578, https:// doi.org/10.1029/1999JC900105.

Müller, D., A. Ansmann, I. Mattis, M. Tesche, U. Wandinger, D. Althausen, and G. Pisani, 2007: Aerosol-type-dependent lidar ratios observed with Raman lidar. J. Geophys. Res., 112, D16202, https://doi.org/10.1029/2006JD008292.

O’Neill, N., T. Eck, A. Smirnov, and B. Holben, 2008: Spectral deconvolution algorithm (SDA) technical memo. NASA Tech. Memo., 39 pp.

Oyola, M. I., and Coauthors, 2019: Quantifying the direct radiative effect of absorbing aerosols for numerical weather prediction: A case study. Atmos. Chem. Phys., 19, 205-218, https://doi.org/ 10.5194/acp-19-205-2019.

Pierangelo, C., A. Chédin, S. Heilliette, N. Jacquinet-Husson, and R. Armante, 2004: Dust altitude and infrared optical depth from AIRS. Atmos. Chem. Phys., 4, 1813-1822, https://doi.org/ 10.5194/acp-4-1813-2004.

Rabier, F., 2005: Overview of global data assimilation developments in numerical weather-prediction centers. Quart. J. Roy. Meteor. Soc., 131, 3215-3233, https://doi.org/10.1256/qj.05.129.

Rodríguez, S., and Coauthors, 2011: Transport of desert dust mixed with North African industrial pollutants in the subtropical Saharan air layer. Atmos. Chem. Phys., 11, 6663-6685, https:// doi.org/10.5194/acp-11-6663-2011.

Sassen, K., Z. Wang, and D. Liu, 2008: Global distribution of cirrus clouds from CloudSat/Cloud-Aerosol Lidar and Infrared Pathfinder Satellite Observations (CALIPSO) measurements. J. Geophys. Res., 113, D00A12, https://doi.org/ 10.1029/2008JD009972.

Saunders, R., and Coauthors, 2018: An update on the RTTOV fast radiative transfer model (currently at version 12). Geosci. Model Dev., 11, 2717-2737, https://doi.org/10.5194/gmd-11-2717-2018.

Scott, N. A., and A. Chedin, 1981: A fast line-by-line method for atmospheric absorption computations: The Automatized Atmospheric Absorption Atlas. J. Appl. Meteor., 20, 802-812, https://doi.org/10.1175/1520-0450(1981)020<0802:AFLBLM> 2.0.CO;2. 
Siméoni, D., C. Singer, and G. Chalon, 1997: Infrared Atmospheric Sounding Interferometer. Acta Astron., 40, 113-118, https:// doi.org/10.1016/S0094-5765(97)00098-2.

Smith, W. L., H. M. Woolf, and W. J. Jacob, 1970: A regression method for obtaining real-time temperature and geopotential height profiles from satellite spectrometer measurements and its application to Nimbus 3 "SIRS" observations. Mon. Wea. Rev., 98, 582-603, https://doi.org/10.1175/1520-0493(1970)098<0582: ARMFOR $>2.3 . \mathrm{CO} ; 2$.

Theil, H., 1950a: A rank-invariant method of linear and polynomial regression analysis: I. Ned. Akad. Wet. Proc., 53, 386-392.

— 1950b: A rank-invariant method of linear and polynomial regression analysis: II. Ned. Akad. Wet. Proc., 53, 521-525.

- 1950c: A rank-invariant method of linear and polynomial regression analysis: III. Ned. Akad. Wet. Proc., 53, 1397-1412.

Tobin, D. C., H. E. Revercomb, J. K. Taylor, R. O. Knuteson, D. H. DeSlover, and L. A. Borg, 2013: Cross-Track Infrared Sounder (CrIS) spectral radiance calibration and evaluations. AIP Conf. Proc., 1531, 724-727, https://doi.org/10.1063/1.4804872.

Welton, E. J., and Coauthors, 2000: Ground-based lidar measurements of aerosols during ACE-2: Instrument description results and comparisons with other ground-based airborne measurements. Tellus, B52, 636-651, https://doi.org/10.3402/ tellusb.v52i2.17124.

_, J. R. Campbell, J. D. Spinhirne, and V. S. Scott, 2001: Global monitoring of clouds and aerosols using a network of micropulse lidar systems. Proc. SPIE, 4153, 151-159, https://doi.org/10.1117/ 12.417040 .

—, and Coauthors, 2002: Measurements of aerosol vertical profiles and optical properties during INDOEX 1999 using micropulse lidars. J. Geophys. Res., 107, 8019, https://doi.org/ 10.1029/2000JD000038.

Weston, P. P., W. Bell, and J. R. Eyre, 2014: Accounting for correlated error in the assimilation of high resolution sounders. Quart. J. Roy. Meteor. Soc., 140, 2420-2429, https://doi.org/ 10.1002/qj.2306.

Yu, H., M. Chin, D. M. Winker, A. H. Omar, Z. Liu, C. Kittaka, and T. Diehl, 2010: Global view of aerosol vertical distributions from CALIPSO lidar measurements and GOCART simulations: Regional and seasonal variations. J. Geophys. Res., 115, D00H30, https://doi.org/10.1029/2009JD013364.

Zhang, J., J. R. Campbell, E. J. Hyer, J. S. Reid, D. L. Westphal, and R. S. Johnson, 2014: Evaluating the impact of multisensor data assimilation on a global aerosol particle transport model. J. Geophys. Res. Atmos., 119, 4674-4689, https://doi.org/ 10.1002/2013JD020975.

J. S. Reid, M. Christensen, and A. Benedetti, 2016: An evaluation of the impact of aerosol particles on weather forecasts from a biomass burning aerosol event over the midwestern United States: Observational-based analysis of surface temperature. Atmos. Chem. Phys., 16, 6475-6494, https://doi.org/ 10.5194/acp-16-6475-2016. 